\title{
Study of the Factors Associated with Llin Use in the Dahras at the Health District of Darou Mousty
}

\author{
Diop Cheikh Tacko ${ }^{1,}$, , Diongue Mamadou ${ }^{2}$, Ka Ousseynou $^{1}$, Bop Martial Coly ${ }^{1}$, Gueye Boubacar $^{1}$, \\ Diagne Maty Camara ${ }^{2}$, Faye Adama ${ }^{2}$
}

${ }^{1}$ Faculty of Community Health at Alioune DIOP University, Bambey, Senegal

${ }^{2}$ Faculty of Médecine, Pharmacy and Dentistry, Cheikh Anta DIOP University, Dakar, Senegal

Email address:

cheikhtackodiop@gmail.com (D. C. Tacko)

${ }^{*}$ Corresponding author

\section{To cite this article:}

Diop Cheikh Tacko, Diongue Mamadou, Ka Ousseynou, Bop Martial Coly, Gueye Boubacar, Diagne Maty Camara, Faye Adama. Study of the Factors Associated with Llin Use in the Dahras at the Health District of Darou Mousty. World Journal of Public Health.

Vol. 5, No. 1, 2020, pp. 12-16. doi: 10.11648/j.wjph.20200501.12

Received: December 26, 2019; Accepted: January 13, 2020; Published: February 4, 2020

\begin{abstract}
The use of Long Lasting Impregnated Nets (LLIN) is still a problem in Senegal despite the efforts made by the National Malaria Control Program (NMCP) and the partners to ensure its availability. The main objective was to study the factors linked to the use of LLIN in the 'dahras' at the health district of Darou Mousty. A cross sectional, descriptive and analytical study on the talibés and the marabouts, was carried out at the health district of Darou Mousty from December 31, 2015 to January 4, 2016. Data were collected at the dahra level using a questionnaire for each target. The questionnaires were administered by individual interview after informed consent. The data covered socio-demographic and environmental characteristics, knowledge of malaria and the LLIN, as well as the usefulness of the latter and the use of other means of protection. The data were entered and analyzed with EPI INFO software version 3.5 .3 with a $95 \%$ confidence interval. In total, 400 talibés and 40 marabouts were enlisted. The mean age of the talibés was $10.7 \pm 2.6$ years; the sex ratio $\mathrm{M} / \mathrm{F}$ of 15.7 . LLIN availability was $36.8 \%$, LLIN utilization rate was $33.9 \%$. The use of LLINs was statistically linked to the seniority of the talibés in the dahra $(p=0.03)$, the female sex $(\mathrm{OR}=10 ; \mathrm{CI}=[1.4-25])$, the place of sleeping $(\mathrm{p}=0.0029)$, the information received on the LLIN by the talibé and the marabout with respectively $(\mathrm{OR}=4.2 ; \mathrm{IC}=[1.3-17.9] ; \mathrm{OR}=3.6 ; \mathrm{IC}=[2.1-6.3])$, the 'Ndiguel' received from the marabout $(\mathrm{OR}=1.8 ; \mathrm{CI}=[1.1-3.3])$, the talibés' knowledge of the usefulness of LLIN as a means of elimination of malaria $(\mathrm{OR}=2.7 ; \mathrm{CI}$ $=[1.5-4.6])$, knowledge of the talibés of the mode of transmission of malaria $(\mathrm{OR}=1.8 ; \mathrm{CI}=[1.0-3,3])$, the use of spirals and insecticides. The use of LLIN in the dahras requires strengthening the knowledge of the talibés and marabouts on malaria and LLIN, its mass and routine distribution and the support of all partners.
\end{abstract}

Keywords: Use, MILDA, Dahras, Darou Mousty, Senegal

\section{Introduction}

Malaria remains the most severe parasitic disease affecting humanity. In 2015, the number of malaria cases worldwide was estimated at 212 million with 429,000 deaths [1]. Most of these deaths had occurred in Africa (92\%) [1]. The number of malaria deaths among children under 5 was estimated at $70 \%$ of the world total. This number is reported to fall to $40 \%$ with a decrease in the incidence of the disease by $31.49 \%$ between 2015 and 2016 [2]. In Senegal, malaria-related mortality in 2015 was 526 deaths, of which 158 in children under 5 years of age, or $30 \%$ of the national total [3]. Children under the age of five account for more than two-thirds of all malaria-related deaths.

However, between 2000 and 2014, the mortality rate of children under five fell by $65 \%$, which represents 5.9 million child lives saved, out of 6.2 million in total [4].

Despite this significant decrease noted, there is a need to strengthen the control strategies recommended by the World Health Organization (WHO) in order to achieve the goal of eliminating malaria. These are the use of long-lasting insecticide-treated mosquito nets (LLINs) and / or the indoor residual spraying of insecticides in vector control, a quick 
access to Rapid Diagnostic Tests (RDTs) in case of suspected malaria and the treatment of confirmed cases by Artemisinin combination Therapies (ACT). However, the evolution of malaria epidemiology requires control strategies targeted at populations particularly with interventions at community level and / or specific places and periods in order to obtain maximum effectiveness. [5, 6]

The Koranic schools, commonly called Dahra, are generally characterized by a plethora of students. The latter are often children brought by their poor parents, unable to participate in the functioning of these structures (clothing, food, housing, etc.). The consequences are poor hygiene and almost the total absence of preventive measures against malaria and faecal diseases.

Very few studies have been done toward the assessment of the prevalence of malaria and the knowledge, attitudes and practices regarding this disease in the Dahra in Senegal.

It is in this context that we undertook this work with as main objective is to study the determinants of the use of LLINs in the Dahra at the health district of Darou Mousty in order to reduce malaria morbidity and mortality.

The Darou Mousty health district is located $250 \mathrm{~km}$ from Dakar, the capital of Senegal. The identified population was 87,600 inhabitants in 2015. The rainy season lasts 3 months, from July to September. Rainwater can stagnate one to two months after the rainy season in some localities in the district.

Women accounted for $49.1 \%$. Children under 5 and pregnant women represented $18.8 \%$ and $3.6 \%$ of the total population, respectively. As for 5 to 14 year-old children, they were estimated at 25,255 or $28.8 \%$ of the total population.

The main activities were agriculture, cattle breeding and trade. There were 15 elementary schools in Darou-Mousty, a total of 60 classes with 3000 students. $65 \%$ of boys and $35 \%$ of girls. There were one high school, three junior high schools including one private; 99 Dahras; two Islamic institutes with more than 1,000 students; 50 literacy classes in the Wolof and Pulaar national languages. The Darou Mousty health district had two health centers (Darou Mousty and Mbacké Kadior), 13 health posts, 30 operational health huts among 39 and 8 community sites.

\section{Methodology}

\subsection{Type of study}

It is a cross-sectional, descriptive and analytical study. The study took place from December 31, 2015 to January 04, 2016. It concerned 5 to 14 year-old talibés and marabouts whose Dahras were in the district of Darou Mousty.

\subsection{Sampling}

For the calculation of the sample size, the following formula was applied:

$$
\mathrm{N}=1.96^{2} \times 0.50 \times 0.50 / 0.05^{2}
$$

Our study focused on 40 clusters, each consisting of 10 talibés and 1 marabout representing 400 talibés.

The sampling frame consisted of the Dahras existing in the distict of Darou Mousty. The three-stage survey was used and focused first on all the 99 'Dahras' in the district of Darou Mousty, then on the talibés.

The choice of Dahras was made by simple random stratified sampling by size.

The Dahras were drawn in proportion according to the size of the classrooms. A total of 40 Dahras were selected. The choice of talibés was made by simple random sampling at the level of each Dahra and for each Dahra for 10 talibés were chosen.

The choice included:

Any talibé aged between 5 and 14 years and living in a Dahra in the Darou Mousty district.

Any marabout residing in the district of Darou Mousty

Sample size calculation

Our study focused on 40 clusters, each consisting of 10 talibés and 1 marabout. Which makes 400 talibés and 40 marabouts.

At each Dahra, a number was given to each talibé. The talibés were drawn by simple random sampling. All the marabouts of the Dahra were interviewed.

1. Dahra or Koranic school: place where the Koran is taught and where the talibés are accommodated

2. Talibé: Wolof term used to designate the child sent to the Dahra to learn the Koran.

3. Marabout: Person in charge of teaching the Koran and supervising the talibés.

4. Ndiguel: Wolof term signifying the order given by the marabout.

5. Sleeping: Place where the talibé sleeps overnight.

6. Use of LLINs: Any talibé who had slept under LLIN the day before the interview.

\subsection{Data Collection Method}

A questionnaire was given to both the talibés and the marabouts of the Dahras. For the implementation of the questionnaires, six interviewers and two supervisors were identified and given a one-day theoretical and practical training as a pre-test. At the end of this pre-test, corrections and clarifications were made on certain multiple choice questions. The questionnaires were dealt with through individual interviews after informed consent. In accordance with the objectives, the questionnaires were divided into four parts. The first focused on the socio-demographic characteristics of talibés and marabouts; the second on the environmental characteristics of talibés and marabouts; the third on the knowledge of the talibés and marabouts about malaria and LLIN and the fourth on the use of other protection means different from LLIN.

\subsection{Analysis}

The data were entered with the epi info 2000 software and analyzed with the $r$ software. Qualitative variables were 
described by frequency and confidence intervals. The average and the standard deviation were used to describe the quantitative variables.

The comparison of the averages was carried out using the Student test. The Chi2 test was used to compare the proportions. The statistical significance threshold was set at $\mathrm{p}$ $<0.05$, and the Odds Ratio (OR) and its 95\% confidence interval were calculated.

\section{Results}

\subsection{Descriptive Study}

\section{Personal Characteristics}

At the end of the data collection, 400 talibés were enlisted. The average age of the talibés was $10.7 \pm 2.6$ years. $90.2 \%$ of the talibés had not attended French school. Boys represented $98.5 \%$. As for the talibés' seniority in the dahras, the average was 35.9 months with a standard deviation of 27.0 months and the median was 36 months. In the dahras, the proportion of talibés who carried out activities outside of apprenticeship was $63.2 \%$. The proportion of talibés sleeping inside the dahra was $96.5 \%$. Talibés who slept on beds with mattresses was $22.8 \%$. The sleeping supports were shared by 1 to 3 talibés in $50.5 \%$ and 4 talibés or more in $49.5 \%$. About $63.3 \%$ of the talibés did not have one. The provision source of LLIN was either parents in $49.3 \%$, and the marabout in $43.1 \%$. In addition, the study showed that 135 talibés slept under LLINs the day before, meaning a utilization rate of $33.9 \%$.

Knowledge of talibés on LLIN and malaria

LLINs were cited in $93.3 \%$ as a means of protecting themselves from mosquito bites and $75.3 \%$ as a means of preventing malaria. Mosquito bites were cited in $80.5 \%$ as the mode of transmission of malaria. The proportion of talibés with a misperception of the transmission of malaria was $26.7 \%$ compared to sun exposure and $6 \%$ compared to consumption of green fruit. In our series, $89.3 \%$ of talibés experienced at least one symptom of malaria. Fever was cited in $76.8 \%$ and Anemia was little known to the talibés $(3.5 \%)$.

\subsection{Analytical study}

Socio-demographic aspects related to the use of LLINs

The average age of talibés who used the LLIN was 11.6 years + or -2.9 compared to 11.1 years \pm 2.2 for those who did not use it $(\mathrm{p}=0.3)$. LLIN use was not related to gender.

The average seniority of the talibés who used the LLIN was 30.7 months \pm 20.7 against 54.2 months \pm 32.4 of those who did not use it $(p=0.03)$. The use of LLINs was linked to the size of the Dahra $(p=0.0068)$. There was a statistically significant relationship between the use of the LLIN, the sleeping place of the talibés and the number of talibés sharing the sleeping support. Talibés who were informed about LLINs were 5.2 times more likely to use LLINs. The talibés were 3.5 times more likely to use LLINs when they were supplied through sanitary channel. The talibés who had received 'Ndiguel' from the marabout were 1.8 times more likely to use LLINs.

Factors associated with the use of LLINs

The talibés who knew that LLIN protected them from malaria had a greater use $(38.8 \%)$ compare to those who did not know (19.2\%). Talibés who knew the mode of malaria transmission were 1.8 times more likely to use LLIN. Knowledge of symptomatology is also associated with use.

\section{Discussion}

The aim of our study was to study the factors linked to the use of LLINs in the Dahra at the Darou Mousty health district. The study included 400 talibés and 40 marabouts who were enlisted in the period from December 31, 2015 to January 04, 2016. The study revealed that the rate of talibés with LLINs was $36.8 \%$. In addition, our study showed that the use of LLINs was linked to socio-demographic, environmental factors and to the level of talibés' knowledge of LLINs.

The study revealed that the rate of talibés with LLINs was $36.8 \%$. This rate is lower than that of the 2014 continuous DHS [13], that of P. Akilimali [8] in DR Congo, that of F. Camara [9] in Guinea and that of S. Mputu [10] in DR Congo, which found $70 \%, 53 \%, 98 \%$ and $75 \%$ respectively. The 2014 continuous DHS [13], F. Camara [9] and JP Kimou [11] found $44 \%, 73 \%$ and $94.7 \%$ respectively.

In our series, age was not a determinant of LLIN use. In fact, there was no statistically significant link between the use of LLINs and age. On the other hand, the study showed that girls used LLIN more than boys. This difference was significant ( $\mathrm{p}$ $=0.009$ ) and was found in the series of J. Kalebo [58] in DR Congo. It was the same for the seniority of the talibés in the Dahra. In accordance with the results of F. Camara [56], education was not associated with the use of LLINs. On the contrary, in the studies of JP Kimou [57], of Netta B. [59] in Tanzania and of I. Ouédraogo [60] in Burkina Faso, the use of mosquito net was statistically linked to the level of education.

Regarding environmental factors, the use of LLINs was significantly linked to the size of the Dahra. In addition, the number of talibés per bed also influenced the use of LLINs. According to WHO standards, an impregnated mosquito net should be used by 2 people to achieve the objectives of UC [55]. These results are lower than those of I Ouédraogo [60] who found the use of $81 \%$ and $59 \%$ respectively when there were fewer than five children and more than five per room. They are superior to those of J. Kalebo [58] who reported $34.5 \%$ LLIN use when there were two children per LLIN.

Regarding the level of knowledge, our results are higher compared to those of J. Kalebo, for the evocation of fever (76.8\% against $69.8 \%$ ) and lower for headaches $(15 \%$ against $45.2 \%$ ). As for the mode of transmission of malaria, our study showed a statistically significant relationship between the knowledge of the transmission mode and the use of LLIN. Thus, the mosquito bite was mentioned by $80.5 \%$ of talibés. These figures are in line with those of Mr. Belay [61] in Ethiopia and I. Ouédraogo [60] in Burkina Faso, who reported $90.2 \%$ and $86.1 \%$ respectively. On the other hand, they are lower than those of S. Mputu [62] (DR Congo) who 
found $92 \%$ and higher than those of F. Camara [56] who reported $78 \%$ in his series. In addition, wrong perceptions of the mode of transmission of malaria were raised by the talibés. These Misperceptions are different from Mr. Belay's [61], from those of F. Camara M. [56] and I Ouédraogo [60] who found stagnant water in $94.5 \%, 42 \%$ and $19.5 \%$ respectively. The source of information was health workers, radio, television, community and marabouts. In the studies of S. Mputu [62] and J. Kalebo [58] In DR Congo, health workers were the main source of information for households. In the series of F. Camara [56] and CT Ndour [63], respectively $22.6 \%$ and $20 \%$ of households had access to information via television. In our study, the main source of information for the talibés was the community because of the configuration and organization of the Dahra which resemble boarding schools. The proportion of talibés who occasionally used LLINs was $13.7 \%$. These data are lower than those of JP Kimou [57] which showed that $75.3 \%$ of those interviewed were still using the LLIN compared to $21.2 \%$ when there were a lot of mosquitoes. In addition, J. Kalebo [58] found $57.8 \%$ of use throughout the year; $22.5 \%$ during the dry season and $19.8 \%$ during the rainy season.

\section{Conclusion}

Significant progresses have been made in the fight against malaria. The combination of proven interventions, including LLINs, has helped to achieve these results. In the Darou Mousty health district, the use of LLINs is still a problem in the dahras with as a corollary, a high malaria incidence compared to the rest of the population.

The unavailability of the LLIN, the 'Ndiguel' du marabout not received by the talibés, ignorance, problems related to maintenance, hooking, bordering of the LLIN and negligence explain this low rate of use among the talibés.

Regarding these results, actions such as the strengthening the knowledge of the talibés and the marabouts on malaria and the LLIN, the reorganization of the dahras, the implementation of a communication plan focused on the identified factors, the strengthening of community dynamics, mass and routine distribution of LLINs should be undertaken, and support from technical and financial partners should be promoted as well.

Table 1. Descriptive study.

\begin{tabular}{|c|c|c|c|}
\hline Features & Absolute frequency $(n=400)$ & Relative frequency $(\%)$ & Confidence Interval 95\% \\
\hline \multicolumn{4}{|l|}{ Educational level } \\
\hline unschooled & 360 & 90.2 & $86.9-93.0$ \\
\hline $\begin{array}{l}\text { Primary school level } \\
\text { bed }\end{array}$ & 39 & 9.8 & $7.1-13.2$ \\
\hline Indoor & 386 & 96.5 & $94.1-98.0$ \\
\hline Outdoor & 14 & 3.5 & $2.0-5.9$ \\
\hline \multicolumn{4}{|l|}{ LLIN availability } \\
\hline Available & 147 & 36.7 & $32.1-41.7$ \\
\hline \multicolumn{4}{|l|}{ Use of LLIN } \\
\hline The " 3 Ts & 118 & 29.5 & $73.5-86.9$ \\
\hline Sometimes & 20 & 13.7 & $8.6-20.4$ \\
\hline Rainy season & 8 & 5.5 & $2.4-10.5$ \\
\hline \multicolumn{4}{|c|}{ Talibes who slept under LLIN the day before } \\
\hline Yes & 135 & 33.9 & $29.3-38.8$ \\
\hline
\end{tabular}

Table 2. Distribution of LLIN use according to the characteristics of the interviewees.

\begin{tabular}{|c|c|c|c|}
\hline \multicolumn{4}{|l|}{ Correct use of LLIN } \\
\hline Dahra size & Yes & No & Total \\
\hline 0 - 50 talibés & $87(39.7 \%)$ & $132(60.3 \%)$ & $219(100.0 \%)$ \\
\hline 51 talibés and more & $48(26.8 \%)$ & $131(73.2 \%)$ & $179(100.0 \%)$ \\
\hline Sleeping place & Yes & No & Total \\
\hline Indoor & $135(35.2 \%)$ & $249(64.8 \%)$ & $384100.0 \%$ \\
\hline Outdoor & $0(0 \%)$ & $14(100.0 \%)$ & $14(100.0 \%)$ \\
\hline Number of talibés per sleeping support & Yes & No & Total \\
\hline 4 and more & $54(27.4 \%)$ & $143(72.6 \%)$ & $159(100.0 \%)$ \\
\hline information received on LLIN & Yes & No & Total \\
\hline Yes & $132(35.5 \%)$ & $240(64.5 \%)$ & $372(100.0 \%)$ \\
\hline No & $3(11.3 \%)$ & $23(88.5 \%)$ & $26(100.0 \%)$ \\
\hline Health channel & Yes & No & Total \\
\hline Yes & $41(41.2 \%)$ & $19(58.8 \%)$ & $60(100.0 \%)$ \\
\hline No & $49(38.0 \%)$ & $80(62.0 \%)$ & $120(100.0 \%)$ \\
\hline No & $24(24.2 \%)$ & $75(75.8 \%)$ & $99(100.0 \%)$ \\
\hline Total & $135(33.9 \%)$ & $263(66.1 \%)$ & $398(100.0 \%)$ \\
\hline
\end{tabular}




\begin{tabular}{llll}
\hline Correct use of LLIN & & & Total \\
\hline Dahra size & Yes & No & Total \\
\hline $\begin{array}{l}\text { Knowledge of the usefulness of LLINs as a } \\
\text { means of malaria elimination }\end{array}$ & Yes & No & $299(100.0 \%)$ \\
Yes & $116(38.8 \%)$ & $183(61.2 \%)$ & $99(100.0 \%)$ \\
No & $19(19.2 \%)$ & $80(80.8 \%)$ & Total \\
Knowledge of fever symptom in malaria & Yes & No & $306(100.0 \%)$ \\
Yes & $113(36.9 \%)$ & $193(63.1 \%)$ & $92(100.0 \%)$ \\
No & $22(23.9 \%)$ & $70(76.1 \%)$ & \\
\hline
\end{tabular}

\section{References}

[1] The Practitioner's Review. Huveaux, Neuilly sur Seine. 2005; 55 (8): 833-840.

[2] World Health Organization. Nature Communications. (Page accessed October 27, 2015 at 11:00 a.m.). World Health Organization (WHO). http://www.who.int/fr/.

[3] Joint WHO/UNICEF 2015 press release: Achieving the Malaria Millennium Development Goal Target; 2015 Sep 17; London, United Kingdom.

[4] Ministry of Health and Social Welfare. National Malaria Control Programme. Bulletin épidémiologique annuel du paludisme au Sénégal. Ministry of Health and Social Action (Senegal). 2014.

[5] Agence Nationale de la Statistique et de la Démographie. Continuous Demographic and Health Survey. Agence Nationale de la Statistique et de la Démographie (Senegal). 2014.

[6] Ministry of Health and Prevention. National Malaria Control Programme. National Strategic Plan against Malaria 20112015. Ministry of Health and Prevention (Senegal). August 2010 .

[7] Ministry of Health and Social Action. National Malaria Control Programme. National Malaria Strategic Plan 20162020. Ministry of Health and Social Action (Senegal). October 2015.

[8] Pierre Akilimali Zalagile. Determinants of the use of insecticide-treated mosquito nets for children under five years of age in the city of Kinshasa 2008 [Dissertation for the Master's Degree in Public Health - Health Economics]. DR Congo: University of Kinshasa School of Public Health; 2008.

[9] Fodé Camara. Evaluation of the use of long-lasting insecticidal nets (LLINs) in the district of Kissidougou Republic of Guinea in 2011. [Dissertation for university graduation]. Côte d'Ivoire: University of Cocody Abidjan; 2011.
[10] Sandrine Mputu Ndongala. Evaluation of the knowledge, attitudes and practices of the inhabitants of Bumbu regarding the use of insecticide-treated mosquito nets (ITNs). Thesis to obtain the title of Graduate in Health Sciences option: Nursing]. DR Congo: National Pedagogical University Department of Health Sciences of Kinshasa Binza; 2009.

[11] Kimou jean Philippe. Evaluation of the use of long-lasting insecticidal nets 21 months after their distribution in the health district of Jacqueville in Côte d'Ivoire. Dissertation for the Master's Degree in Economics and Management of Health Systems in Developing Countries. Côte d'Ivoire: University of Cocody; 2010.

[12] Jean Kalebo Watanga. Degree of adherence to the use of insecticide-treated nets in Kalebo. [Thesis for the public health license]. DR Congo: Institut supérieur des techniques médicales de Bukavu; 2009.

[13] Ministry of Health and Prevention Senegal. National Malaria Control Programme. National Malaria Survey 2008-2009 (ENP II). Ministry of Health and Social Action (Senegal). July 2009.

[14] Netta Beer, Abdullah S Ali, Don de Savigny. System effectiveness of a targeted free mass distribution of long lasting insecticidal nets in Zanzibar (Tanzania) 2010; 10.1186/1475-2875-9-173.

[15] Issa Ouédraogo. Study of the determinants of the use of long-lasting insecticidal nets after a distribution campaign in 2009 in the health district of Diébougou, Burkina Faso. Dissertation for the interuniversity diploma]. Côte d'Ivoire: University of Cocody; 2010.

[16] Belay M, Deressa W. Use of insecticide treated nets by pregnant women and associated factors in a pre-dominantly rural population in northern Ethiopia. Tropical med Int health 2008; 13 (110): 1303-13.

[17] C. T Ndour, O. Ba, N. M. Manga, M. L. Fortes, D. Nyamwasa and P. S. Sol. Malaria: Knowledge, attitudes and practices of heads of households of the rural population of Gossas, Senegal. Paris: Springer; 2006. 99 (4): 290-293. 